\title{
PERFORMANCE STANDARDS FOR PHYSICAL EDUCATION - A NECESSITY OF THE CURRICULAR REFORM
}

\author{
Virgil TUDOR $^{1^{*}}$ Vera PÎSLARU ${ }^{2}$ \\ ${ }^{1}$ National University of Physical Education and Sport, Faculty of Physical Education and Sport, Bucharest, \\ Romania \\ 2 "Ștefan Odobleja" Theoretical High School, Bucharest, Romania \\ *Corresponding author: verapislaru@yahoo.com
}

https://doi.org/10.35189/dpeskj.2021.60.2.5

\begin{abstract}
This paper addresses the topic of the necessity to develop performance standards adjusted to the current needs and requirements of high school students for the physical education and sport subject. The research highlights the necessity to reform curricular documents, adapt learning contents and thus develop performance standards consistent with students' interests, concerns and abilities. Establishing the profile of the future high school graduate in accordance with the requirements of today's society and based on the eight key competencies should represent the regulatory component of the national curriculum. Physical education and sport should contribute and respond to the transformations that take place in society and prepare current generations of high school students for social and professional integration. Students who graduate from high school need to possess a high level of key competencies that equip them for lifelong learning. It is important for the educational reform in the Romanian education system to be achieved through a clear analysis of the values and competencies that the young generation of students must acquire in order to thrive in a global society. The conclusions point out the necessity to reform curricular documents in Romanian education, and the implementation of performance standards for the physical education and sport subject can support the alignment of the Romanian education system with the European education system.
\end{abstract}

Keywords: curriculum, performance standard, physical education, high school.

\section{Introduction}

In our country, the term "curriculum" was mainly used after the Romanian Revolution of 1989, when the education system made the transition from an authoritarian system to a system in line with the democratic society to which it aspired. Curriculum reform, which aims to correlate the Romanian education system with European objectives and standards, has become primordial for pre-university education.

The concept of curriculum designates the meticulous preparation of an educational action or an entire educational programme, with the interrelationships between its objectives and the ways of achieving and evaluating it (Cucoş, 2002). The curriculum indicates the fundamental path for planning and designing the education system.

In a broad sense, the curriculum refers to all the educational processes and learning experiences through which students pass during their school years. In a narrow sense, the curriculum includes all regulatory school documents where essential data on the educational processes and learning experiences that the school offers to students are recorded. This is usually called a formal or official curriculum. (Crişan et al., 1998)

The literature provides classifications of the curriculum according to several criteria, but this paper will address only two of them, which are thought to be relevant for the current topic: 
- According to the form of education:

- formal curriculum;

- non-formal curriculum;

- informal curriculum.

- According to the typology of the national curriculum applied in the Romanian education system:

- core curriculum;

- curriculum at the school's decision.

The main documents of the school curriculum are: the curriculum, the syllabus, the textbook and auxiliary guidebooks. All these documents undergo regular changes and adaptations, depending on the requirements of education systems and the needs of society for a global and integrative development (Varol \& Imamoglu, 2014).

Educational reform is based on the idea that school is a social institution where students acquire competencies necessary for integration and adaptation to the transformations that occur in society, the school environment becoming a place of training and personal, professional and social development in close relationship with family and local community.

In the current paradigm, that of student-centred learning, the reform of curricular documents starts from knowing what to do, knowing how to do, knowing when to do and wanting to do. Transdisciplinarity and interdisciplinarity underlie the training of future graduates who will be able to transfer and apply in everyday life the knowledge and skills acquired during physical education and sport lessons. (Ennis, 2015).

\section{Topic Addressed}

The first project intended to reform the national curriculum in Romania reflected the educational option for the student-centred approach and the application of an active and interactive teaching method connected to the current pedagogical paradigm, which highlights the student's active role in the process of knowledge while promoting the interactive social dimension of learning.

In the curriculum development during the 1990s, key transdisciplinary skills anticipated key areas of competence and were the benchmark for organising school curricula for grades 1-8. Similarly, operational categories for the formulation of competencies were the benchmark for the organisation of high school curricula (1999-2001 version).

The concerns regarding the curricular reform in our country materialised in 1998, when the training profile of the compulsory education graduate was developed as part of the reference framework for the national curriculum.

The current Romanian education system is focused on building competencies, which represents the ability to perform a certain activity in a given context by reference to welldefined standards and objective outcomes. The acquisition and training of competencies is reflected in the knowledge, skills and attitudes that underlie the graduate's formation profile.

In our opinion, it would be appropriate for this defined profile of the graduate to be adjusted to current social requirements, to be guided by principles and values in accordance with social needs. The outcomes of high school education should aim to train graduates able to decide on their own careers, trace the paths of their personal development and actively integrate into 
social life. The adaptation of curricular documents should be seen in interdisciplinary and transdisciplinary terms that contribute to the complex formation of student's personality, and this approach should underpin the formation of the future graduate.

The concept of educational standard is not well defined in the literature and has been a subject of controversy in the last three decades. The term "standard" first appeared in the educational context in 1862, with the promulgation of the British Education Law. This term is defined as follows: a norm or set of norms that regulate the quality, characteristics, form, etc. of a product; a document where these rules are recorded ("Standard", 1998).

The educational process quality is analysed through curricular performance standards that represent evaluation criteria. Standards are concise statements of what students should demonstrate they can achieve at the end of an education level in the field of content covered by a particular subject. They define the competencies that students should develop at a certain stage of school education.

The purpose of educational standards is to contribute to the development and quality control of the education system.

In an attempt to delimit the concept, the following types of standards have been identified:

- Educational standards;

- Content standards;

- Learning opportunity standards;

- Performance standards.

Educational standards encompass content standards, learning opportunity standards and performance standards.

Content standards represent the description of students' acquisitions corresponding to the school subjects in the curriculum areas, which teachers have to take into account in their teaching-evaluation activity. They apply to all students without any discrimination, including students with special educational needs. However, performance standards are differently applied to students with special needs, but in most countries, this category of students do not have to meet national performance standards.

Learning opportunity standards or educational context standards refer to the quality of programmes as well as the human and material resources needed in the teaching, learning and evaluation process.

Performance standards, including performance descriptors and grading criteria, are the basis for a successful educational reform. Standards specify the expected outcomes but also lead to the way of evaluating them and implicitly to determining the methods of intervention to increase the educational process quality. Content standards and learning opportunity standards can be redefined according to the achievement or failure to achieve performance standards.

The relationship between curricular components is shown in Figure 1. 


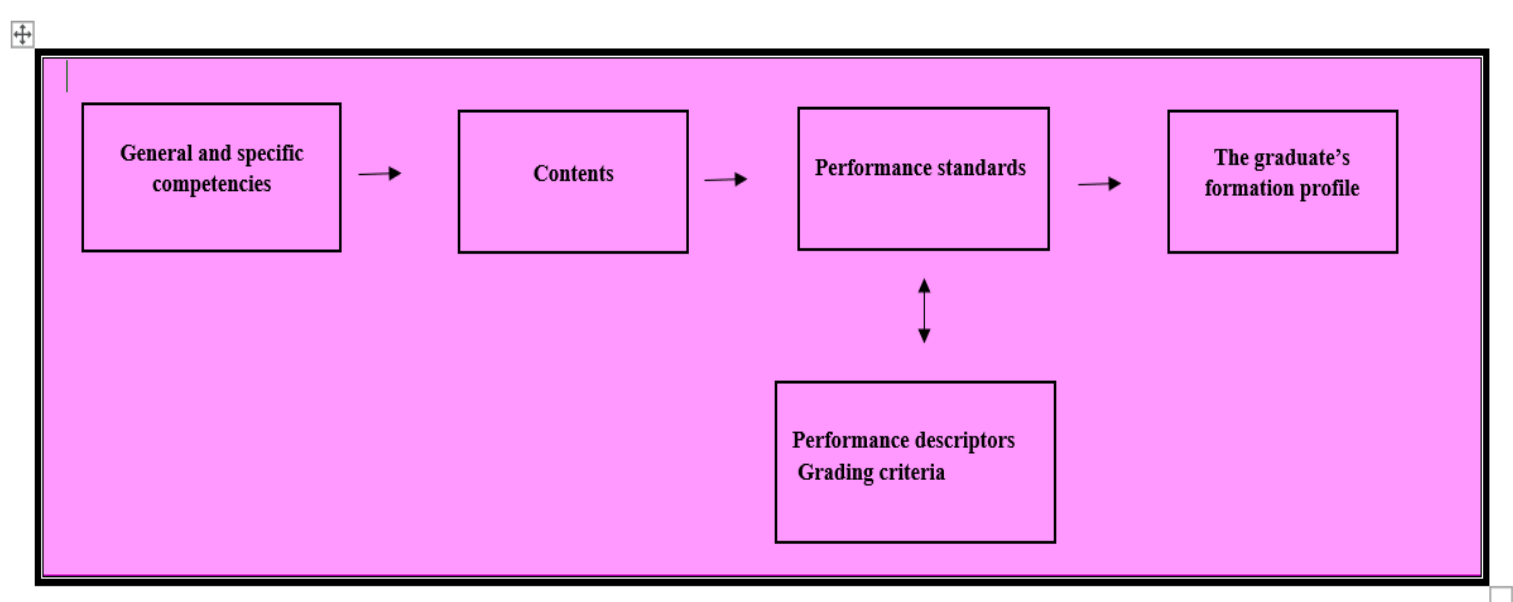

Figure 1. The relationship between curricular components

Educational actions are guided by performance standards in order to support and stimulate learning, to develop and train students. Performance standards are materialised in performance indicators, which represent observable actions and behaviours. Indicators can be used to measure progress in achieving performance standards.

There is interdependence between the three types of standards because the development and implementation of content standards would not be relevant in the absence of a clear definition of the student's level of performance. Also, learning opportunity standards would not be effective in the absence of content and performance standards.

The role of standards is to measure and guide when the standard is not reached, by developing ways to achieve or even exceed standards in the future.

Without properly developed standards, neither the quality of the education system nor curricular reforms can be effectively assessed. The constant use of standards at all education levels indicates the performance reached by students, allowing the intervention and application of effective methods in case of failure to meet the required standard (Erwin \& Castelli, 2008).

The performance standard represents the level to be reached, which is why it is advisable to meet a number of requirements when establishing them.

- A first requirement is to formulate them in accordance with the general and specific competencies of the school curricula for each subject and year of study.

- A second requirement is to ensure the link between content and evaluation. In order to verify the achievement of standards, evaluation tests are established, which can also be applied in the physical education and sport lesson accompanied by scales with standardised values at national level (Vaccari et al., 2021).

- Standards should be described simply and concisely so that they lead to student motivation. The contents leading to the fulfilment of standards and learning activities should be enjoyed by the students to whom they are addressed, thus increasing the attractiveness of the lessons as well as the conscious and active participation of students (Fu et al., 2013).

- Standards should help verify and highlight student progress from one educational level to another. 
- Another requirement is to take into account all the particularities of students, including their residential areas (Chillon et al., 2011; Zhang et al., 2021; Carrel et al., 2012).

School physical education and sport can and must contribute to the formation of graduates able to: solve problems by correlating their knowledge in different fields; exploit their own experiences; develop their capacity for active integration into different sociocultural groups (family, friends, professional groups); build and develop key functional competencies for their social success (communication, analysis, optimal decision-making); cultivate their expressiveness and sensitivity in order to grow personally and professionally.

Physical education has as general objectives: maintaining an optimal health status, providing harmonious physical development, educating motor qualities, building motor skills and abilities including the ability to exercise independently, educating personality traits. The development of a new up-to-date curriculum for physical education and sport should focus on forming the future graduates' habit to practice physical exercise throughout their lives while understanding the importance of maintaining an active and healthy lifestyle (Penney \& Jess, 2004; Xu et al., 2021).

The physical education and sport subject goes, together with the entire Romanian education system, through this curricular reform, with modifications, adaptations and revisions of the main curricular documents. We give a brief overview of the documents presenting standards for physical education and sport over the last 30 years.

The first references to standards were made in 2003, when the purposes, curriculum and structure of compulsory education were reviewed. In this context, the National Evaluation and Examination Service published the "Evaluation Standards for Grade 4, Grade 8 and Grade 12" for all subjects in the curriculum, including physical education and sport.

In 2003, with the approval of the Revised School Physical Education Curriculum for Grades 1-2 by Order of the Minister of Education no. 4686/05.08.2003, reference objectives, examples of learning activities, contents and curricular performance standards for primary education (referred to at the end of the 2nd grade) appear in the structure of the school curriculum, together with the framework objectives. The curriculum does not specify a minimum or maximum level but only that curricular performance standards are mandatory.

We present below the framework objectives and standards as mentioned in the Revised School Physical Education Curriculum for Grades 1-2.

Framework objectives

1. Maintaining students' optimal health and increasing their ability to adapt to environmental factors $\rightarrow$ Standard: Exemplification of two activities performed in order to maintain their own health status;

2. Harmonising one's own physical development and preventing possible deviations from the correct posture $\rightarrow$ Standards: Execution of a physical development complex consisting of four exercises adapted to individual capabilities; Presentation of an exercise for preventing deviations from the correct posture, for the back, lower limbs and abdomen;

3. Extending one's own background of basic (practical-utilitarian and sports) motor skills and developing the related motor qualities $\rightarrow$ Standard: Application of two basic motor skills (running-jumping or throwing-catching) during a relay race; 
4. Independent practice of physical exercise, games and different sports $\rightarrow$ Standard: Application of two practical-utilitarian skills (between crawling, climbing, transport, traction) during a relay race;

5. Manifestation of team and competitive spirit according to a system of accepted rules $\rightarrow$ Standards: Demonstration of the development level of motor qualities in relation to the values determined by predictive evaluation at the beginning of the education level; Application of basic sports skills acquired in a particular sport while observing specific regulations and adequacy to the system of relationships with partners and opponents.

In 2005, the Physical Education School Curriculum for Grade 4 is published as Appendix 2 to the Order of the Minister of Education and Research no. 3919/20.04.2005, at the end of which the same curricular performance standards as aforementioned are presented.

For lower secondary education, no performance standard is provided in the school curricula for physical education and sport.

For upper secondary education, in the "Evaluation Standards for Grade 4, Grade 8 and Grade 12 " issued in 2003, five evaluation standards are established with two minimum and maximum thresholds that are mentioned below:

Standard 1

To act efficiently in motor activities using basic motor qualities and skills but also those specific to the studied sport at an optimal level of exercise volume, intensity and complexity

Minimum: To perform simple motor acts and actions with low indices of exercise volume, intensity and complexity, and low indices of manifestation of motor qualities

Maximum: To perform motor acts and actions combined with high indices of exercise volume, intensity and complexity, and high indices of manifestation of motor qualities

Standard 2

To integrate specific motor skills in the competitive or non-competitive practice of studied sports

Minimum: To perform separately, in game conditions, the main elements and technical/ tactical procedures specific to studied sports

Maximum: To apply, in game conditions, all the elements and technical procedures specific to studied sports, based on the analysis of changing situations and reactions of the opponents or partners in compliance with the specific regulation

Standard 3

To apply the basic information about hygiene, health, prevention of physical disability and the beneficial effects of natural strengthening factors on the human body in both school activity and daily life

Minimum: To identify the basic notions of hygiene, health, prevention of poor physical attitudes and the beneficial effects of natural strengthening factors on the human body

Maximum: To assess one's physical development over time and apply, in various climatic conditions, the basic information acquired about hygiene, health and prevention of health issues in order to eliminate any possible disharmony specific to puberty

Standard 4

To practise independently physical exercises and the sports played in high school, including during leisure time 
Minimum: To practise independently activities recommended by the teacher and exercises for general physical development

Maximum: To apply the knowledge and skills acquired during physical education and sport classes to leisure activities and participate in competitions and races in self-organisation conditions

\section{Standard 5}

To participate in sports activities during or outside the school schedule, showing team spirit and fair play

Minimum: To fulfil simple responsibilities and functions within the activities carried out, identifying basic provisions of the technical and refereeing regulations of studied sports

Maximum: To participate actively and responsibly in sports games and competitions within the groups and teams set up at the classroom level while acting according to the rules and norms established by the technical and refereeing regulations of studied sports

Currently, the physical education and sport curriculum for high school provides 1 hour per week in the common core for all grades except the 10th grade - Sciences profile, which benefits from 2 hours per week. The school physical education and sport curriculum in force for high school dates from 2009, and the evaluation of high school students is done in accordance with the National School Evaluation System for Physical Education and Sport published in 1999. The school curriculum in force does not specify performance or evaluation standards.

Thus, it can be seen that the Romanian education system for the physical education and sport subject lacks both coherence in formulating performance standards and continuity in establishing them from one education level to another, while also noting their absence from the school curricula in force.

The need to develop and establish performance standards for each year of study in our education system must become a priority of decision-makers, given that standards are evaluation benchmarks for students, teachers, parents and evaluators of the education system.

The better defined and prepared a curriculum, the more performance standards are reached, and the differences that may appear during the teaching process are removed, taking into account that, in the rural areas of many countries, there are no specialised teachers for all school subjects, including physical education and sport (Chen et al., 2017).

At European level, the physical education and sport subject is part of the national curriculum in all Member States of the European Union. In 2011, the European Commission's Communication on Sport expressed concern about the quality of physical education and sport programmes in some Member States and recommended reforming them. In this regard, France and Portugal proposed to increase the number of physical education and sport lessons, while Greece and Hungary diversified the educational offer in schools. In Romania, the last reform of the school curricula for physical education and sport took place in 2017, when the school curriculum for physical education and sport at the lower secondary level was approved, and the high school curriculum is expected to change starting with the 2021-2022 school year.

Ensuring the same level of basic education for all students and bringing the Romanian school's level of performance closer to the performance of education systems in developed countries become the goals pursued by performance standards, including for physical education and sport. 
Awareness of the importance of physical education activities is reflected in the policies of many countries that provide a sufficient number of classes for these activities but particularly in compulsory physical activities provided in the curriculum (Bassett et al., 2013).

Physical education and sport can contribute to the education and training of students but especially adolescents towards a healthy lifestyle, keeping them away from harmful temptations in society. Student participation in formal activities during lessons but also in nonformal extracurricular activities successfully contributes to adopting active and healthy living rules (Harrison \& Narayan, 2003; Cattuzzo et al., 2016).

The Eurydice Network has produced a report entitled "Physical Education and Sport at School in Europe" (European Commission, 2013), whose main objective is to describe the status of physical education and sport activities at school in 30 European countries. The report can be seen as a beginning of the European Commission's attempts to observe and highlight the weaknesses and strengths of school physical education and sport in European countries.

Student progress in physical education and sport is evaluated just as in other subjects, and this fact exists in many countries. It has been found that students' abilities in physical education and sport are evaluated in a non-formal way only in a small number of European countries. In Malta and Norway, for example, non-formal evaluation is applied to primary school students, while in Ireland, this type of evaluation can be found in both primary and secondary education.

As for some clear recommendations on the evaluation methods to be used, most European countries do recommend such a set of rules, with the exception of Belgium and Iceland, where educational institutions are free to establish the most appropriate methods to be applied.

At the end of each school year, many countries use a procedure that consists in creating and providing reports that include the results of student evaluation in all school subjects, therefore in physical education and sport too. Some of these countries have developed a system at central level, which involves the existence of evaluation steps. The purpose of this system is to assist teachers in the evaluation process, representing a harmonised tool for evaluating student performance at national level. This system, which is implemented at national level, also offers the possibility to make an indicative comparison of the obtained results.

\section{Conclusion}

In our opinion, this system that involves evaluation steps is actually based on the existence of performance standards. We consider it appropriate to reform curricular documents so that they include performance standards for each year of study and thus the progress made by students during their school years could be highlighted.

Based on the above information, we have come to the conclusion that the curricular reform is a real necessity in the current Romanian education system. Thus, it appears that school curricula are mandatory to be developed in accordance with the future graduate's current needs, hence the necessity to develop performance standards. Performance standards are actually evaluation steps used as a benchmark at national level, which allow easy summarisation and then the interpretation and comparison of students' results at the end of each grade and education level. These performance standards become a common reference system for students across the country. 
Another conclusion is that the reform of curricular documents must ensure a unified concept of school curricula and implicitly performance standards. It is thus necessary to develop specific performance standards addressing each education level within the curricula for school physical education and sport.

\section{Authors' Contributions}

Both authors have equally contributed to this study.

\section{References}

Bassett, D. R., Fitzhugh, E. C., Heath, G. W., Erwin, P. C., Frederick, G. M., Wolff, D. L., Welch, W. A., \& Stout, A. B. (2013). Estimated energy expenditures for school-based policies and active living. American Journal of Preventive Medicine, 44(2), 108-113. https://doi.org/10.1016/j.amepre.2012.10.017

Carrel, A. L., Bowser, J., White, D., Moberg, P., Weaver, B., Hisgen, J., Eickhoff, J., \& Allen, D. B. (2012). Standardized childhood fitness percentiles derived from school-based testing. The Journal of Pediatrics, 161(1), 120-124. https://doi.org/10.1016/j.jpeds.2012.01.036

Cattuzzo, M. T., dos Santos Henrique, R., Ré, A. H. N., Santos de Oliveira, I., Melo, B. M., de Sousa Moura, M., de Araujo, R. C., \& Stodden, D. (2016). Motor competence and healthrelated physical fitness in youth: A systematic review. Journal of Science and Medicine in Sport, 19(2), 123-129. https://doi.org/10.1016/j.jsams.2014.12.004

Chen, A., Zhang, T., Wells, S. L., Schweighardt, R., \& Ennis, C. D. (2017). Impact of teacher value orientations on student learning in physical education. Journal of Teaching in Physical Education, 36(2), 152-161. https://doi.org/10.1123/jtpe.2016-0027

Chillon, P., Ortega, F. B., Ferrando, J. A., \& Casajus, J. A. (2011). Physical fitness in rural and urban children and adolescents from Spain. Journal of Science and Medicine in Sport, 14(5), 417-423. https://doi.org/10.1016/j.jsams.2011.04.004

Crișan, A., Cerkez, M., Singer, M., Oghină, D., Tacea, F., \& Sarivan, L. (1998). Curriculum național pentru învățământul obligatoriu - Cadru de referință [National curriculum for compulsory education - Reference framework]. Corint.

Cucoș, C. (2002). Pedagogie [Pedagogy] (Ed. a 2-a). Polirom.

Ennis, C. D. (2015). Knowledge, transfer, and innovation in physical literacy curricula. Journal of Sport and Health Science, 4(2), 119-124. https://doi.org/10.1016/j.jshs.2015.03.001

Erwin, H. E., \& Castelli, D. M. (2008). National physical education standards: A summary of student performance and its correlates. Research Quarterly for Exercise and Sport, 79(4), 495-505. https://doi.org/10.1080/02701367.2008.10599516

European Commission. (2013). Physical education and sport at school in Europe: Eurydice report. Luxembourg. doi: 10.2797/49648

Fu, Y., Gao, Z., Hannon, J., Shultz, B., Newton, M., \& Sibthorp, J. (2013). Influence of a health-related physical fitness model on students' physical activity, perceived competence, and enjoyment. Perceptual and Motor Skills, 117(3). https://doi.org/10.2466/10.06.PMS.117x32z0

Harrison, P. A., \& Narayan, G. (2003). Differences in behavior, psychological factors, and environmental factors associated with participation in school sports and other activities in adolescence. Journal of School Health, 73(3), 113-120.

https://doi.org/10.1111/j.1746-1561.2003.tb03585.x 
Penney, D., \& Jess, M. (2004). Physical education and physically active lives: A lifelong approach to curriculum development. Sport Education and Society, 9(2), 269-287. https://doi.org/10.1080/1357332042000233985

Standard. (1998). In Dicționarul Explicativ al Limbii Române [Explanatory Dictionary of the Romanian Language]. Univers Enciclopedic.

Vaccari, F., Fiori, F., Bravo, G., Parpinel, M., Messina, G., Malavolta, R., \& Lazzer, S. (2021). Physical fitness reference standards in Italian children. European Journal of Pediatrics, 180, 1789-1798. https://doi.org/10.1007/s00431-021-03946-y

Varol, Y. K., \& Imamoglu, A. F. (2014). Comparatively analyzing the physical education curriculum in elementary education according to teacher opinions in Turkey and England. Journal of Physical Education and Sport, 14(1), 98-105. DOI: 10.7752/jpes.2014.01016

Zhang, F., Bi, C., Yin, X., Chen, Q., Li, Y., Liu, Y., Zhang, T., Li, M., Sun, Y., \& Yang, X. (2021). Physical fitness reference standards for Chinese children and adolescents. Scientific Reports, 11: 4991. https://doi.org/10.1038/s41598-021-84634-7

$\mathrm{Xu}$, D., Zheng, Y. Y ., \& Jia, Y. L. (2021). The bibliometric analysis of the sustainable influence of physical education for university students. Frontiers in Psychology, 12: 592276. https://doi.org/10.3389/fpsyg.2021.592276 